\title{
PROTOCOL DEVELOPMENT: LEVEL OF PREVENTIVE ACTION METHOD, CONSIDERING THE PREVENTIVE ENVIRONMENTS IN CONSTRUCTION WORKS
}

\author{
Antonio José CARPIOำ, María de las Nieves GONZÁLEZ ${ }^{*}$, \\ Inmaculada MARTÍNEZ ${ }^{2}$, María Isabel PRIETO ${ }^{3}$ \\ ${ }^{1}$ Departamento de Mecánica aplicada e ingeniería de proyectos, Escuela Ingeniería Industrial \\ y Aeroespacial de Toledo, Universidad de Castilla La Mancha, Toledo, Spain \\ ${ }^{2}$ Departamento de Construcciones arquitectónicas y su control, Escuela Técnica Superior \\ de Edificación, Universidad Politécnica de Madrid, Madrid, Spain \\ ${ }^{3}$ Departamento de Tecnología de la Edificación, Escuela Técnica Superior de Edificación, \\ Universidad Politécnica de Madrid, Madrid, Spain
}

Received 17 April 2020; accepted 31 July 2020

\begin{abstract}
The techniques for preventing risk have traditionally been analyzed on an individual basis, it being highly complex to apply preventive procedures across the board in construction works. This implies the necessary risk assessment based on the common factors of Safety at Work, Industrial Hygiene, Ergonomics and Psychosociology. This work analyzes and classifies the environments which characterize the building process: absolute (initial), documentary, construction, social and life cycle, and identifies the technical-documentary processes associated with each one. Finally, a new risk assessment method adapted to building works is proposed, called "Level of Preventive Action", by means of a new mathematical formula which encompasses Safety at Work, Industrial Hygiene, Ergonomic and Psychosociological factors. It is based upon the development of the William T. Fine method, adapting it to construction works, with the incorporation of six parameters to explain the degree of correction. It consolidates and connects environment parameters to determine the preventive action level of the construction work, with the objective of establishing the levels of preventive control required to achieve an optimum prevention situation. The results of comparison between the environments in the implementation of the new risk assessment methodology during the construction process in a real building work are shown.
\end{abstract}

Keywords: health and safety, risk assessment, construction, place of work, preventive environment, preventives parameters.

\section{Introduction}

In the early days of health and safety at work, risk assessment methodologies focused more on the negative results (sickness and injuries) rather than the positive results (health and safety) which were significantly more abstract concepts (Molina, 2006; Swuste et al., 2020). Risk prevention techniques were analyzed on an individual basis; with the result that prevention procedures were put forward to cover Safety at Work, Industrial Hygiene, Ergonomics and Psychosociology and it was highly complex to apply preventive procedures across the board. Despite the existence of various risk assessment systems, no tools have been found which make it possible to obtain a global rating for a construction project as a whole (Forteza et al., 2016; Pin- to, 2014; Simanaviciene et al., 2014; Salanova et al., 2005; Reyes et al., 2014; Oliveira, 2010; Claudino Véras, 2012; Carpio et al., 2017). Nevertheless, many research projects incorporate a climate of safety due to the uncertainty generated by human behavior in risk prevention (Gürcanli \& Müngen, 2009; Xia et al., 2020), it being necessary to assess risk based on the common factors of Safety at Work, Industrial Hygiene, Ergonomics and Psychosociology (Mohamed et al., 2009; Zhao et al., 2016; Mushayi et al., 2018). It is significant that a risk assessment that can be based on different aspects and conclude on a single approach. Under this criterion, Lucchi (2016) unifies different parameters that otherwise will be usually evaluated in

*Corresponding author. E-mail: mariadelasnieves.gonzalez@upm.es 
a separately to point out specific aspects of the building. This indicates the need to establish these types of evaluations in field of occupational health and safety.

In order to prevent accidents at work, it is essential to incorporate risk prevention in all phases of business activity (Act 31 of $8^{\text {th }}$ November 1995), implementing an occupational hazard prevention plan which uses risk assessment as a tool in order to perform preventive planning and fight against accidents at work. By way of key factors in accidents, the associated causes of occupational accidents have been identified and quantified by Haslam et al. (2005). As such, they obtained the problems derived from employees or the work team ( $70 \%$ of accidents), problems at the place of work (49\%), defective equipment (including personal protective equipment) (56\%), problems with the suitability and condition of the materials (27\%), and shortcomings in risk management (84\%) (Haslam et al., 2005). Mihić (2020) adds the Workers Movement, as approximately $20 \%$ of accidents occur while the worker moves around the construction site. Asilian et al. (2018) considered it necessary to investigate the fundamental causes of the unsafe behaviors of workers in the construction sector thus creating a new effective tool. It is essential to approach health and safety beyond bureaucratic and financial roles, greater involvement of all agents making up a construction project being necessary (Haslam et al., 2005) and the consultation and participation of employees and collaboration between employers and employees being vital (Segarra et al., 2017). Which implies a need for a safety culture both in the construction project environment and in the construction process environment (Birhane et al., 2020; Minh \& Yingbin, 2019). In this regard, Lucchi (2020) proposes a methodology with screening, observation, analysis and expertise criteria, based on the effectiveness and satisfaction of workers, with regard to the prevention of occupational risks to guarantee cost reduction and improve the efficiency of the procedure that defines.

Several risk assessment methodologies have been defined which generalize in their definition of the fundamental parameters which quantify the level of risk. Among others, Jannadi and Almishari (2003) studied risk assessment in construction activities, defining risk as a measure of probability, severity and exposure to the hazards of an activity. Barandan and Usmen (2006) adopted the same approach, based on the definition of risk as the product of probability (frequency) and severity. Williams (1993) believes that risk depends on two factors; the probability of occurrence and impact quantified as the consequences for the employee and his or her environment. The mathematical expression of the above would be $R=P$ - I (Williams, 1993). Faber and Stewart (2003) also define the same concept in technical risk as the expected consequences associated with a specific activity. Taking into account an activity with a single event, the risk $R$, is the probability of this occurring $P$, multiplied by the consequences, $C$. In other words: $R=P \cdot C$ (Faber \& Stewart, 2003). Nevertheless, these are the parameters proposed by
Williams (1993). Fine that are closest to the real circumstances. Starting with the product of probability, exposure and consequences, a parameter is incorporated, which is inversely proportional, to justify the corrective action (Espinheira et al., 2020; Carpio \& González, 2017). Although such parameters have a qualitative and quantitative definition that are very difficult to interpret and apply to construction works (Carpio et al., 2017).

Quantifying the consequences of risk is a difficult task due to the fact that the same accident may produce multiple consequences and there may be different perceptions when evaluating the severity of the same injury (Pinto et al., 2012). As such, analyzing the complete process of a construction project starts with the planners' initial proposals, includes the needs of the builder and developer, and ends by looking at the behavior of the workers themselves. Larsson and Field (2002) studied the risks of falling from heights in the different professions and different scenarios which coincide in the construction process, proposing that prevention should occur in the design phase, in the preliminary building solutions, in task planning and supervision. Likewise, Forteza et al. (2016) establish the need to gather information from different viewpoints due to the special characteristics of the construction process. Such information can be taken from the particular characteristics of the project, documentation, environmental conditions, safeguards, machinery, etc. Performing a prior analysis, before an accident can occur, anticipating incidents. They also point out the lack of available information concerning construction environments. This method gathers information about the environment of a construction work based on the players, their roles, the type and phases of the project; with the resulting evaluation of the general safety conditions, the task, the safeguards and the tools. This all facilitates prioritization in general or one-off operations (Forteza et al., 2016).

Within the climate of safety and safe conduct, Gillen et al. (2002) evaluated construction workers' perception of injury with regard to the climate of safety in the workplace, psychological demands at work, freedom of choice and support for colleagues. Praising safe conduct and safe work in a culturally acceptable manner (Gillen et al., 2002) to which Gao et al. (2019) incorporated the incidence of the parameter of the safe behavior of workers, extraversion, kindness, neuroticism and conscience, in the development of a construction work.

Mohamed et al. (2009) explain that it is widely accepted that unsafe conduct is intrinsically linked to workplace accidents, there being a positive correlation between safe employee conduct and the climate of safety in construction areas. Consequently, the attitude of construction workers towards safety is influenced by their perceptions of risk, management, safe roles and work procedures (Mohamed et al., 2009; Zhao et al., 2016; Mushayi et al., 2018). Expanding on this concept, Mohammadi and Tavakolan (2020) described the influence of behavioral archetypes of different types of workers that identified in unsafe construction climates, pointing out construction projects, 
construction managers, security means, economic interests, unsafe actions as determinants in the generation of an unsafe climate and workplace accidents.

Studies into risk prevention are highly diverse and currently include wider approaches. Not only do they cover the basic concepts of the parameters of probability and consequences (Faber \& Stewart, 2003; Williams, 1993); or frequency and degree of exposure to risk (Fine, 1971), but preventive analysis extends to technical design parameters (Hardison et al., 2020) during the initial development phases of a construction project (Asilian et al., 2018) and the productive development phase (Martínez-Aires et al., 2018; Minh \& Yingbin, 2019). It also encompasses the analysis of construction procedures for different types of materials, supporting tools, machinery, safety systems and for employee safety training (Forteza et al., 2017), covering personal relationships, behavior roles, climate of safety and safe behaviors (Lucchi, 2020; Engeda et al., 2020), it being an essential objective to lay the foundations for defining a model that brings together all of the options for analysis in the field of construction works (Carpio \& González, 2017; Carpio et al., 2017; Carpio \& González, 2020).

The objective of this study is to establish the correlation that exists between the different stages associated with the process of planning and producing a construction project by means of developing and adapting the parameters defined in the mathematical methodology of William T. Fine. To do so, it is proposed to designate these stages with a more appropriate name that allows identifying the preventive parameters for each stage, which is called the construction process environment. These stages correspond to the different environments that justify the development of a construction: initial environment (conception of the project), documentary environment (analysis of the project), constructive environment (material and human resources), social environment (social relations) and environment of building life (use and maintenance). Such correlation justifies the proposal of a new risk assessment method adapted to construction works which is called Level of Preventive Action $\left(L_{p a c}\right)$; with a new risk assessment mathematical formula adapted to construction works (Carpio, 2017; Carpio \& González, 2020). Finally, this risk assessment methodology is implemented in a real construction. Data and references are taken during all phases of the construction process. The graphic results show the relationship between the different environments of the construction process. This justifies the mathematical procedure proposed by the new method and the need to globally observe the level of preventive action required in for each construction phase and each evaluation risk.

\section{Proposal of environments and parameters of the new assessment method}

The mathematical formula from William T. Fine's method (Fine, 1971) has been developed and adapted to construction works taking into account the assessment of risk prevention techniques: Safety at Work, Industrial Hygiene,
Ergonomics and Psychosociology; and proposing the identification of the construction process environments. All aimed at analyzing the deviation in the level of prevention from the initial premise and determining the level of prevention that needs to be incorporated when carrying out the work in order to improve the conditions of the design, construction and social relationships. The risk parameters defined in each project environment and proposed for this new risk assessment method adapted to building construction works, are as follows:

Absolute Environment $\left(E_{a b}\right)$ (initial design and project drafting stage. Basic risk parameters):

- Probability $(P)$ : estimation of the risk tolerance with regard to the probability of an injury occurring.

- Consequences $(C)$ : estimation of the risk tolerance with regard to the expected consequences of the injury that could occur.

- Absolute Risk $\left(R_{a b}\right)$ : is the direct relationship of the probability for the consequences (P.C). Estimation carried out at the start of the building works using the Health and Safety at Work Plan drawn up by the construction company. This is the documentary environment, absolute in nature and serves as the base for comparing the other parameters.

Documentary Environment $\left(E_{d}\right)$ (contractor contract stage. Basic risk parameters, physical and geometrical risk parameters):

- Relative Risk $\left(R_{r}\right)$ : preventive parameter which interprets the complexity of the building safety associated with the work unit and increases the absolute risk value.

- Borderline Risk $\left(R_{b}\right)$ : preventive parameter which interprets the location of the work unit and its incidence in the environment; and increases the absolute risk value.

Construction Environment $\left(E_{c}\right)$ (implementation project stage. Basic risk parameters, physical and geometrical risk parameters, human and construction resources parameters):

- Degree of Exposure (E): parameter which assesses the amount of time the worker takes to complete the work unit and is consequently exposed to risk several times during the performance of that work unit; and increases the absolute risk value.

- Economic Capacity $\left(E_{c}\right)$ : parameter which assesses the amount of economic resources in building hazard prevention systems; and decreases the absolute risk value.

Social Environment (Es) (implementation project stage. Basic risk parameters, physical and geometrical risk parameters, construction resources parameters, and parameters concerning the emotional state and participation):

- Participative Interest $\left(P_{i}\right)$ : parameter which assesses the Participative Interest of the different players involved in a construction project, obtaining their perception of its health and safety; decreases the absolute risk value. 
- Level of Satisfaction $\left(L_{s}\right)$ : parameter which considers general behavioral aspects, frames of mind and human attitudes which significantly influence, or could significantly influence, the generation of risks; and decreases the absolute risk value.

Live Cycle Environment $\left(E_{l c}\right)$ (phase of delivery to users, parameters of coexistence, use and maintenance of the building). This environment is based on sub-environments that do not fall within the building process (guarantees and responsibilities environment of a building construction; documentary, legal and economic environment; use and maintenance environment; and neighborhood relations environment). Due to its complexity requires a detailed study and adapted to the circumstances of the use and maintenance within the life cycle of the building.

\section{Methodology. Proposed mathematical formula for new assessment method}

An initial starting point is proposed that is based on the mathematical Eqn (1) for assessing and controlling risk defined by William T. Fine (Fine, 1971) in which risk score $R$ is analyzed as the degree of danger based on: $P$ - the probability, $C$-consequences of an accident, $E$ - the degree of employee exposure, and $J$ - justification of action against the risk is based on the cost factor $\left(C_{F}\right)$ and degree of correction $\left(D_{C}\right)$ that the preventive action requires Eqn (2). This method is extremely difficult to adapt to construction works due to the implicit challenge of interpreting and applying its qualitative and quantitative parameters.

$$
\begin{aligned}
& R=P \cdot C \cdot E \\
& J=\frac{P \cdot C \cdot E}{C_{F} \cdot D_{C}}=P \cdot C \cdot\left(\frac{E}{C_{F} \cdot D_{C}}\right) .
\end{aligned}
$$

The second approach is based on the different risks related to the different project environments such as the relationship between the documentary influence, construction influence and social influence; the parameters are linked based on the different phases of risk which occur during the execution of the project. $R_{r}$ - The relative risk and $R_{b}$ - Borderline Risk are associated with the documentary phase of the project; $E$ - the degree of employee Exposure and $E_{c}-$ Economic Capacity with the procurement phase of the project in the construction environment; and $P_{i}-$ the Participative Interest of the employee and $L_{s}$ - Level of Satisfaction with the implementation phase of the project and the Social Environment (Eqn (3)):

$$
L_{p a c}=P \cdot C \cdot\left(\frac{R_{r} \cdot R_{b} \cdot E}{E_{C} \cdot P_{i} \cdot L_{s}}\right)=R_{a b} \cdot E_{p a c} .
$$

In Eqn (3) for Level of Preventive Action $\left(L_{p a c}\right), R_{a b}-$ absolute risk; $E_{p a c}$ - environment of Level of Preventive Action.

Finally, the analogies between both formulations are established, looking at the fundamental environments in construction works, which encompass the different stag- es of the construction process, which in turn enable the definition of the associated risk phases together with the preventive parameters inherent in them.

\subsection{The mathematical method of William T. Fine}

This method was developed by William T. Fine (1971) by the name of Mathematical Evaluation for Controlling Hazards and was published in 1971 by the US Naval Ordnance Laboratory. This method establishes a formula for linking factors of control and calculating the risk, giving a numeric assessment to the importance of the corrective measure to prevent the hazard. The correction priorities are established based on the risk rating (Eqn (1)). An additional formula establishes the estimated cost and effectiveness of the corrective action in preventing the risk, and determines whether the cost is justified (Eqn (2)).

It is important to mention that this method was developed in a practical way in the nautical instruments sector and that the methodology refers to the fact that it can be applied universally with the adaptations and corrections that are considered to be appropriate.

The expression which defines the Eqn (1), links $R$ the Risk score (which depends on the anticipated injury over time) based on the direct relationship between the product of $P$ - the Probability of the event (which depends on the accident anticipated in a certain situation of risk), $C$ - the Consequences (which depend on the injury anticipated based as a result of the accident anticipated) and $E$ - the Exposure to risk (which depends on the situation of risk over time) (Eqn (4)). Table 1 contains the numerical values for each of the parameters of the equations.

$$
\begin{aligned}
& \frac{\text { Anticipated injury }}{\text { Time }}=\frac{\text { Anticipated accident }}{\text { Situation of risk }} . \\
& \frac{\text { Anticipated injury }}{\text { Anticipated accident }} \cdot \frac{\text { Situation of risk }}{\text { Time }} .
\end{aligned}
$$

Table 2 displays the range of values which are most commonly used for this method and the criteria for acting with regard to the magnitude of danger.

Equation (5) establishes whether the cost of the corrective action to reduce the danger is justified from de William T. Fine's method (Fine, 1971). In order to achieve this, two parameters are added which are inversely proportional to the degree of risk and which reflect the $C_{F}-$ Estimated Cost to correct the hazard and the $D_{C}$ - Degree of Correction of the preventive action. It should be noted that the elements of the numerator of this formula are the same as in the Risk Score (Eqn (1)).

$$
J=\frac{R}{\text { Amount of prevention }}=\frac{P \cdot C \cdot E}{C_{F} \cdot D_{C}},
$$

where: $J$ - Justification.

All the dimensionless values are replaced in the formula in order to determine the justification value. If the resulting value is greater than the critical value of 10 the corrective action to reduce the hazard is considered to be 
Table 1. Values for the parameters to calculate the risk score

\begin{tabular}{|l|c|l|c|l|c|}
\hline \multicolumn{2}{|c|}{ Probability } & \multicolumn{2}{c|}{ Consequences } & \multicolumn{2}{c|}{ Exposure } \\
\hline \multicolumn{1}{|c|}{ Definition } & Value & \multicolumn{1}{c|}{ Definition } & Value & \multicolumn{1}{c|}{ Definition } & Value \\
\hline Most likely & 10 & Catastrophe & 100 & Continuously & 6 \\
\hline Quite possible & 6 & Multiple fatalities & 50 & Frequently & 3 \\
\hline Unusual & 3 & Fatality & 25 & Occasionally & 2 \\
\hline Remotely possible & 1 & Extremely serious injury & 15 & Unusually & 1 \\
\hline Extremely emote & 0.5 & Disabling injuries & 5 & Rarely & \\
\hline Practically impossible & 0.1 & Minor cuts & 1 & Very rarely & 0.5 \\
\hline
\end{tabular}

Table 2. Action in relation to degree of danger

\begin{tabular}{|l|l|l|}
\hline \multicolumn{1}{|c|}{ Magnitude of risk $R$} & \multicolumn{1}{c|}{ Degree of danger } & \multicolumn{1}{c|}{ Action against risk } \\
\hline Greater than 400 & Very high risk & Immediate halt of dangerous activity \\
\hline Between 200 and 400 & High risk & Immediate correction \\
\hline Between 70 and 200 & Notable risk & Urgent necessary correction \\
\hline Between 20 and 70 & Possible risk & It is not an emergency, but the risk must be corrected \\
\hline Less than 20 & Acceptable risk & No need for correction \\
\hline
\end{tabular}

justified. For a value lower than the critical value of 10 the cost considered for the corrective action is not justified.

Both the values given to each parameter and the critical value to justify action are based on experience in decision making and in the economic situation at the time of the calculation. However, the method enables the range of values and critical value to be increased depending on the type of accidents to be studied, economic situation and assessment of prevention systems.

\section{Analysis and classification of environments}

In the building process, based on an extensive bibliography, three periods are identified which determine the type of prevention: the documentary period, which relates to the project characteristics and organization of the work (Allen \& Iano, 2019; Act 31 of $8^{\text {th }}$ November 1995; Castellano, 2008; Larsson \& Field, 2002); the project implementation period which encompasses the construction systems (Fakhratov et al., 2020; Forteza et al., 2016; Jung et al., 2008; Zou et al., 2007; Haslam et al., 2005) and that concerned with social influence (Lucchi, 2020; Abbas et al., 2013; Salanova et al., 2007; Haslam et al., 2005; Úbeda de Mingo, 2002); and the period of use and maintenance which involve in new owners or users with the rules of coexistence (Tepeli et al., 2019). The documentary period is one of the fundamental parts of accident prevention, there being studies which indicate that more than $42 \%$ of designs may be related to accidents which occurred in the construction industry (Segarra et al., 2017; Jannadi \& Almishari, 2003).

Where preventive action in the documentary period are concerned, the geometrical definition of the construction is established along with its associated theoretical characteristics in the part corresponding to the initial design period of the building; the respective work units and construction systems, with an evaluation of each and their legal conformity; in the part associated to the project implementation documentation work (Act 31 of $8^{\text {th }}$ November 1995; Castellano, 2008; Larsson \& Field, 2002). Inside the documentary period includes the definition given by the construction company during the implementation and monitoring of the construction and prevention systems; within the budgetary margins of the work execution contract. All these technical definitions must be considered within the same context or environment for the preventive action. The preventive action in the documentary period is determined as a Documentary Environment. Both documents have been prepared during periods of different characteristics: Project of Execution and Contracting of Work. Therefore, the preventive action of the documentary environment is divided into two: Initial or Absolute Environment, during the project phase; and Documentary Environment, during the contract phase. The mandatory documents, regarding prevention, defining the documentary period, in the case of Spain, are the Health and Safety at Work Study (or Basic Study) like Annex for the Building Execution Project and the Health and Safety at Work Plan the Health and Safety at Work Plan produced by the construction company (Act 31 of $8^{\text {th }}$ November 1995).

In preventive action related to the project implementation period, the development characteristics of the different stages of a construction work are established, applying the theoretical, geometrical, legal and construction concepts set out in the prior documentation. In the project implementation period two fundamental interconnected periods are established: the construction period and the social period. The construction period is where the conditions of construction complexity are defined based on the work units, their location and interdependence with other work units. This influences the performance of the workers in delivering such work units, and, as a consequence, 
the budgetary progress of the project (Tepeli et al., 2019; Forteza et al., 2016; Jung et al., 2008; Zou et al., 2007; Haslam et al., 2005). The social period is where the interest, participation, motivation level and emotional state of the workers are defined as fundamental elements associated with the delivery of the units of work and the different construction systems (Lucchi, 2020; Fakhratov et al., 2020; Bhandari et al., 2020; Abbas et al., 2013; Salanova et al., 2007; Haslam et al., 2005; Úbeda de Mingo, 2002). The definitions that characterize both periods are clearly different: of technical and social consideration. In this case, from the point of view of preventive action, two environments of preventive action must be considered: the constructive environment and the social environment.

Finally, it is important to understand as a building process the period from the delivery of the building to its new owners (or users). It is the period of use and maintenance in which legal conditions, reform actions and neighborhood relationships are established. The preventive action includes all the environments of the construction process: Absolute Environment (documentation of the building), Documentary Environment (conditions about use and maintenance), Constructive Environment (reform actions) and Social Environment (neighborhood relationships). In this case, the preventive action should be considered as a single environment called the Life Cycle Environment.

Likewise, in the analysis of each environment, different risk phases are classified which are associated to the different phases of the building construction process (Allen \& Iano, 2019; Castellano, 2008). However, due to the analysis of the different risk phases related to health and safety in construction works, a phase equivalent to the analysis, construction budget and procurement process has been incorporated. As such, there are five distinct phases in the building construction process along with their respective associated risks in the field of prevention. Based on the preventive action for the associated risks, preventive environments are defined in the building process (Table 3 ).
The Documentary Environment is associated with the first two phases of the building construction process. It covers everything from the developer's initial interest in investing in the construction of a building to the technical-economic options and the associated technical-legal definitions. The mandatory and preventive documents defining the Documentary Environment are the Basic Plan, the Building Plan and the Health and Safety at Work Study (and the Basic Health and Safety at Work Study). The first phase (preliminary design) and the second phase (drafting of the Basic and Execution Project of the building), both with the associated project risk, are defined by the basic concepts of risk based on the probability of an event and its consequences occur; since no more information available.

The Documentary Environment is associated with first, second and third phases of the building construction process. It covers everything from the developer's initial interest in investing in the construction of a building to the technical-economic options and the associated technicallegal definitions. Defining the conditions of constructive complexity based on the work units, their location and interdependence with other work units, which influences the workers' performance and the budgetary development of the work. The mandatory and preventive documents that define the Documentary Environment are the Urban Works License issued by the City Council, the Occupational Health and Safety Plan drafted by the Contractor, the Contract for the execution of the work and the Certificate of Approval of the Health and Safety at Work Plan. Regarding the associated risks, information contemplated in the conditions of the Project and the Contract is added. To the parameters of probability and consequences, the physical conditions of the work are incorporated by the manipulation of the materials and the geometric conditions by the location of the workplace.

The project implementation period (defined by the construction and social periods) is associated with the

Table 3. Proposal environments preventive action

\begin{tabular}{|c|c|c|c|c|c|}
\hline Period & \multicolumn{2}{|c|}{ Building Stage } & Associated Risk & \multicolumn{2}{|c|}{ Preventive Environment } \\
\hline \multirow[t]{3}{*}{ Documentary } & \multicolumn{2}{|c|}{$\begin{array}{l}\text { Stage 1: Design and Market Research. } \\
\text { Preliminary design. }\end{array}$} & \multirow[t]{2}{*}{ Project Risks } & \multirow{2}{*}{\multicolumn{2}{|c|}{ Absolute $\left(E_{a b}\right)$}} \\
\hline & \multicolumn{2}{|c|}{$\begin{array}{l}\text { Stage 2: Drafting of the Basic and Execution } \\
\text { Project of the building. }\end{array}$} & & & \\
\hline & \multicolumn{2}{|c|}{$\begin{array}{l}\text { Stage 3: Analysis of work and developer- } \\
\text { contractor contract. }\end{array}$} & $\begin{array}{l}\text { Project Risks and Contractor } \\
\text { contract }\end{array}$ & \multicolumn{2}{|c|}{ Documentary $\left(E_{d}\right)$} \\
\hline \multirow[t]{2}{*}{$\begin{array}{l}\text { Project } \\
\text { Implementation }\end{array}$} & \multirow{2}{*}{\multicolumn{2}{|c|}{ Stage 4: Work Execution and Workers Contract. }} & $\begin{array}{l}\text { Project Risks, Contractor } \\
\text { contract and Work Execution }\end{array}$ & \multicolumn{2}{|c|}{ Constructive $\left(E_{c}\right)$} \\
\hline & & & $\begin{array}{l}\text { Project Risks, Contractor } \\
\text { contract, Work Execution and } \\
\text { Social Relationships }\end{array}$ & \multicolumn{2}{|l|}{ Social $\left(E_{s}\right)$} \\
\hline \multirow[t]{4}{*}{ Building Use } & \multirow{4}{*}{$\begin{array}{l}\text { Stage 5: Building } \\
\text { Delivery to New } \\
\text { Owners }\end{array}$} & Building Book & Risk as Built Definition & Absolute & \multirow[t]{4}{*}{ Life Cycle $\left(E_{l c}\right)$} \\
\hline & & $\begin{array}{l}\text { Use and Maintenance } \\
\text { Conditions }\end{array}$ & Documentary Risk & Documentary & \\
\hline & & reform actions & Work Execution Risk & Constructive & \\
\hline & & neighborhood relationships & Social Risk & Social & \\
\hline
\end{tabular}


fourth phase of the building construction process. Being the environments corresponding to this period, the Constructive Environment and the Social Environment.

Where preventive action in the Construction Environment is concerned, the development characteristics of the different phases of work in a construction project are established; applying the theoretical, geometrical, legal and construction systems established by the existing documentation of the Execution Project. Defining the conditions of construction complexity based on the work units, their location and interdependence with other work units, which influences the workers' performance and the budgetary progress of the project by the existing documentation of the Construction Contract. Likewise, during the execution of the work, there are situations of exposure to risk by workers and implementation of constructive systems for the individual and collective safety of workers. Both situations may be different or modified during the work. The mandatory and preventive documents defining the construction environment are the Construction contract between the developer and the contractor, the Building Plan, the Health and Safety at Work Plan produced by the construction company and the Certificate of Approval of the Health and Safety at Work Plan. Also, in the Construction Environment (execution of the work) the documentation is prepared according to the conditions of the work, so it is determined by observation and technical experience.

Where preventive action in the Social Environment that the participative and emotional interest of the different players and construction workers are defined, along with the workers' level of motivation as fundamental elements associated with delivering the work units and the different construction systems and preventive means of safety and health. In the fourth phase of the building construction process, the associated work risks are defined by the basic parameters, geometrical and physical parameters, exposure to risk by workers, construction resources parameters and parameters related to workers' collaboration, personal satisfaction and emotional estates.

With regard that the building is handed over to the new users, in the Life Cycle Environment, associated with the fifth phase of the building construction process, the risk is defined by the life cycle risk which includes different parameters to those encompassed by the aforementioned risks. This period includes, in an initial phase, the warranties and responsibilities of the agents participating in the planning, development, implementation and delivery of the building within the legally established period. The following phase begins with the use and maintenance by the building users based on the training given to the Residents' Association which is jointly managed alongside a Property Management company (Ley 8/2013, 2013). This phase involves the correct use and adequate maintenance of the building, with the aim of maintaining the functional and aesthetic features inherent to the building that was designed and built in a good state of repair over time, by following the instructions for use and maintenance for the finished building (Real Decreto 314/2006, 2006). The pace at which the building ages will depend, to a large extent, on its correct use and on compliance with the maintenance requirements. The life cycle risk parameters are defined by use and maintenance concepts which cover documentary risks, use and maintenance risks, neighborly relations, financial risks and legal risks. These parameters are not inherent to the new construction process; as such reference should be made to a more detailed study outside of the field of construction projects.

The environments encompass all phases of the building construction process and identify the different risks associated with each phase over the course of the project. Likewise, each risk phase is defined by the characteristic prevention parameters (Figure 1).

Absolute Environment $\left(E_{a b}\right)$ :

- First Stage: Design and Market Research. Preliminary design.

- Initial risk phase.

- Basic risk parameters.

- Second Stage: Drafting of the Basic and Execution Project of the building.

- Project risk phase.

- Basic risk parameters.

- Physical and geometrical parameters of the building.

Documentary Environment $\left(E_{d}\right)$ :

- Third Stage: Analysis of work and developer-contractor contract.

- Procurement risk phase.

- Basic risk parameters.

- Physical and geometrical parameters of the building.

- Construction and human resources parameters.

Construction Environment $\left(E_{c}\right)$ :

- Fourth Stage: Project implementation.

- Building risk phase.

- Basic risk parameters.

- Physical and geometrical parameters of the building.

- Construction and human resources parameters.

Social Environment $\left(E_{s}\right)$ :

- Fourth Stage: Project implementation.

- Social relationships risk phase.

- Basic risk parameters.

- Physical and geometrical parameters of the building.

- Construction and human resources parameters.

- Level of satisfaction and participation parameters.

Life Cycle Environment $\left(E_{l c}\right)$ :

- Fifth Stage: to users. Building book.

- Life cycle risk phase

- Documentary, use, maintenance, neighborly relations, economic and legal risk parameters. 


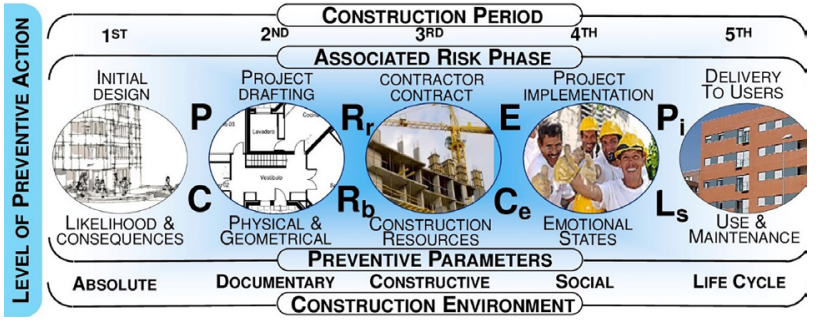

Figure 1. Environment outlines and its associated breakdown (Own elaboration)

\section{Identification of preventive parameters}

Based on an analysis of construction environments, the risk phases in the different construction phases in the building process have been identified. Different prevention parameters are inherent to the said risk phases. The parameters associated to the construction implementation process are:

- Basic risk parameters.

- Physical and geometrical parameters of the building;

- Human and construction resources parameters;

- Level of Satisfaction and participation parameters.

\subsection{Basic risk parameters}

The basic Risk parameters $-R$ reflect the estimated risk tolerance in terms of the probability - $P$ of the injury occurring and the expected Consequences $-C$ of the injury that may occur (Gómez-Cano et al., 1996), which are related in direct proportion (Eqn (6)):

$$
R=P \cdot C \text {. }
$$

This risk analysis is performed at the start of building execution using the Health and Safety at Work Plan drafted by the construction company. It is the base for comparing the other parameters, since it constitutes the $E_{a b}$ - Absolute Documentary environment and serves as a base for comparing the other parameters (Eqn (7)):

$$
R=P \cdot C=E_{\text {absolute }} .
$$

\subsection{Documentary risk parameters}

When assessing the risks involved in a construction project, the documentary risk parameters are associated with the technical, legal, building, economic and temporary definitions for the building development, which are used to determine the exact geometry of the building, the construction systems, project planning, work units, project budget, availability of the materials, the facilities, legal conditions and graphical information (Gao et al., 2019; Larsson \& Field, 2002). The parameters considered at this stage relate to the complexity of the work units in terms of their geometrical definition, and to the interdependencies between them with regard to their physical definitions.

Geometrical risk is a preventive parameter which interprets the complexity of the construction safety as- sociated with the work unit and increases the risk value. The quantification values depend on the degree of complexity of the construction phase of the work unit and on the impact of the risk prevention techniques on the environment. It is a $R_{r}$ - Relative Risk that depends on factors such as graphics, reconsideration, the number of employees, their skills, the height of the support facilities, machinery required, the weight of the material used and its manageability.

Physical risk is a preventive parameter which interprets the interdependence of the work unit in relation to the safety of the work location and which increases the risk value. The quantification values depend on the location of the work unit and on the impact of the risk prevention techniques on the environment. It is a height and $R_{b}$ - Borderline Risk which depends on the position in relation to the ground and on the position of the worker in relation to the edge.

This risk analysis is performed during the site inspection to assess risk and depends on the physical and geometrical definition of the building. It is the construction environment and is characterized by its assessment of the degree of danger of the construction risk. It has a directly proportional relationship:

$$
\begin{aligned}
& E_{\text {documentary }}=R_{\text {relative }} \cdot R_{\text {bordeline }} ; \\
& R=P \cdot C \cdot R_{r} \cdot R_{b} ; \\
& R=E_{\text {absolute }} \cdot E_{\text {documentary }} .
\end{aligned}
$$

The $E_{d}$ - Documentary Environment spans the first and second phases of the building construction process (Eqn (8)). The risk phases take into consideration the basic risk parameters, physical parameters and geometrical parameters of the building (Eqns (9) and (10)).

\subsection{Construction risk parameters}

When assessing the risks involved in a construction project, the documentary risk parameters are associated with the contractual document between the property and the construction company in accordance with the terms established in the construction project, the safety study and the rest of the technical documentation. The parameters considered at this stage relate to the construction company's contribution in terms of human and material resources and auxiliary systems of work. Based on an estimate of the worker's degree of exposure to the risk and the economic and practical resources allocated to risk prevention (Fine, 1971).

The risk due to the degree of exposure assesses the amount of time that a worker uses to complete the work unit and is consequently exposed to risk several times during the performance of that work unit. The quantification values depend on whether or not during the time taken to perform the work unit situations of risk have repeatedly occurred; placing the worker's manual ability against company interests (Forteza et al., 2017; Abdurrahman, 2009). Consciously or not, workers repeat work roles. 
This implies that dangerous situations can be controlled or circumvented through the worker's experience. This is a $R_{e}$ - risk due to exposure which is construction-related with a directly proportional relationship.

The risk associated with $R_{c r}$-construction resources is based upon William T. Fine's method (Fine, 1971) regarding the justification of the corrective action in terms of the cost factor and the degree of correction. The amount of economic resources in preventive construction systems is assessed. Economic capacity is a parameter which corrects the documentary risk parameters and the degree of exposure, which means that it has an inversely proportional relationship:

$$
\begin{aligned}
& E_{\text {construction }}=R_{\text {exposure }} \cdot R_{\text {construction resources }} \\
& R=P \cdot C \cdot R_{r} \cdot R_{b} \cdot R_{e} \cdot \frac{1}{R_{c r}} \\
& R=E_{\text {absolute }} \cdot E_{\text {documentary }} \cdot E_{\text {construction }} .
\end{aligned}
$$

The $E_{c}$ - Construction Environment encompasses the third phase of the building construction process (Eqn (11)). The risk phases take into account the basic risk parameters, the physical and geometrical parameters of the building; and parameters related to construction and human resources (Eqns (12) and (13)).

\subsection{Social risk parameters}

The social parameter assesses the workers' interest, participation and frame of mind as fundamental elements associated with the completion of work units and implementing different construction systems. It estimates the importance of the work (Nogareda, 1988) and evaluates the job position variables in order to improve personal safety and that of the environment (Lucchi, 2020; Chavarría, 1986).

The $R_{p}$ - Participation Risk evaluates the combined action of the workers in preventing risk, this being extremely important due to the changing activities in building work. The quantification values depend on the observation of the interest and the participation in prevention matters; whether they are sufficient or whether greater involvement by the workers is required in terms of preventive measures. The worker's perception of health and safety at an individual, team and social level is obtained by means of a survey. This interview contains four questions on the emotional state and six questions on the perception of risk in safety and health (Salanova et al., 2007), defined in the protocol of the method of the Level of Preventive Action (Carpio, 2017). The Participative Interest is a relative parameter which analyzes behavior and attitude at both an individual and group level, correcting the documentary and construction parameters, which means that it has an inversely proportional relationship.

The $R_{s}$ - risk due to the level of satisfaction assesses direct staff interaction in order to obtain answers by means of a survey which reveals the perception of the worker's level of satisfaction (Lee et al., 2020; Cuchí, 2010). Such observation considers general aspects of behavior and human attitude which significantly influence, or could significantly influence, the generation of risks. The said observation may be used to establish the immediate guidelines for on-site action concerning social influence parameters as well as establishing an initial, characteristic value concerning the psychosocial conditions observed at the time of the on-site assessment. The Level of Satisfaction is a parameter which corrects the documentary and construction parameters, which means that it has an inversely proportional relationship:

$$
\begin{aligned}
& E_{\text {social }}=R_{\text {participation }} \cdot R_{\text {satisfaction }} ; \\
& R=P \cdot C \cdot R_{r} \cdot R_{b} \cdot R_{e} \cdot \frac{1}{R_{c r}} \cdot \frac{1}{R_{p}} \cdot \frac{1}{R_{s}} \\
& R=E_{\text {absolute }} \cdot E_{\text {documentary }} \cdot E_{\text {construction }} \cdot E_{\text {social }} \cdot
\end{aligned}
$$

The $E_{s}$ - Social Environment encompasses the fourth phase of the building construction process (Eqn (14)). The risk phases take into account the basic risk parameters, the physical and geometrical parameters of the building, the parameters related to construction and human resources and the parameters related to participation and personal satisfaction (Eqns (15) and (16)).

\section{Analogies with William T. Fine's Method}

William T. Fine's method proposes two formulas (Fine, 1971). The first determines the degree of danger or risk score and depends on the parameters of probability, the consequences and the degree of exposure (Eqn (1)). The second formula proposes justification criteria for corrective action based upon two parameters, the cost factor and the degree of correction of the preventive action (Eqn (2)).

The formula proposed in the new risk assessment method called $L_{p a c}$ - Level of Preventive Action, takes into account the analysis of the building work environments and determines the degree of danger based upon the parameters of probability, the consequences and the degree of exposure to the risk. At the same time, it proposes justification criteria for corrective action based upon six parameters: $R_{r}$ - Relative Risk, $R_{b}$ - Borderline Risk and $E$ - the degree of Exposure in a directly proportional relationship; and $E_{c}$ - the Economic Capacity, $P_{i}$ - Participative Interest and $L_{s}$ - Level of Satisfaction in an inversely proportional relationship (Eqn (3)).

The Relative Risk, Borderline Risk and degree of Exposure refer to the cost factor; and economic capacity refers to the correction degree of the William T. Fine method (Fine, 1971). Bearing in mind that the degree of correction proposed by William T. Fine is unsuitable for application in building construction projects due to its high subjectivity and inaccuracy (Carpio \& González, 2017), parameters of a psychosocial nature are incorporated (Participative Interest and Level of Satisfaction), which, to a large extent, correct documentary and construction parameters. The application parameters of the William T. Fine method are 
currently out of date. The current reality of the construction process differs enormously with respect to the determining factors posed by William T. Fine (Carpio et al., 2017).

\section{Results and discussion}

The mathematical formula from William T. Fine's method (Fine, 1971) has been developed and adapted to construction works, incorporating various parameters which take risk assessment into account concerning Safety at Work, Industrial Hygiene, Ergonomics and Psychosociological factors.

The adaptation and development of the formula from William T. Fine's method does not remove its essence which is the justification of the corrective action. Furthermore, as William T. Fine's method indicates, the quantification values used in the new Level of Preventive Action method are the most interesting in terms of the numbering they follow and the possible range of results that they offer, it being possible to amend them according to the working environments being observed for assessment.

This article offers one of the approaches to the new methodology for assessing occupational hazards adapted to building works, called the Level of Preventive Action. In this article, prevention environments for the development and extension of the William T. Fine (Fine, 1971) methodology are considered as new points of observation in the field of prevention.

The new method has been implemented in the whole process of a construction work, in every execution phase. Complete technical data related to prevention and occupational health and social-related data concerning the worker's condition and risk perception in the building environment have been gathered.

It is fundamental to learn to observe people, from the perspective of different construction environments, in their places of work, and to identify unsafe or deficient actions (Cuchí, 2010; Silva et al., 2013), since the prevention of accidents and management of risk is a social priority in the construction industry. Workplace accidents generate economic losses for companies, the authorities, workers and society in general (Paolillo et al., 2020; Gomes de Oliveira, 2010), which is why accidents at work require analysis that focuses upon the overall construction environment (Lucchi, 2020; Sanni-Anibire et al., 2020; Avdiu et al., 2020; Lucchi, 2016; Lucchini \& London, 2014; Úbeda de Mingo, 2002; Gomes de Oliveira; Claudino Véras, 2012).

\subsection{Implementation}

Based on the theoretical basis stated in the previous sections, on the foundations of observation in the field of prevention, which have served as a basis for the definition of the parameters in the different environments of the construction process: absolute, documentary, constructive and social. Becomes necessary the practical application and implementation of these foundations and formulation about the reality of the construction process.
The new model has been applied to a real construction. The different parameters of the new formula were adapted to the construction process and received analysis criteria's. Based on the observation environments the characteristic values for evaluating the parameters are as follows:

- In the Absolute Environment $\left(E_{a b}\right)$ the Probability $(P)$ and Consequences $(C)$ parameters are those estimated in the mandatory risk assessment prior to the start of the works. Both parameters will serve as a comparative basis with the Level of Preventive Action $\left(L_{p a c}\right)$ based on the product of both $(P \cdot C)$ and which is called Absolute Risk $\left(R_{a b}\right)$.

- On the Record $\left(E_{d}\right)$ and within the Level of Preventive Action $\left(L_{p a c}\right)$, the observation characteristics regarding the Relative Risk parameter $\left(R_{r}\right)$, are based on the graphical quality of the plans, the necessary restatements, qualification of the operator, necessary tools, the weight of the material and its handling. The Bordeline Risk $\left(R_{b}\right)$ parameter is based on the height or depth of the work plan to the ground and the distance to the edge of the building. Both parameters interpret risks of a physical and geometric nature of the construction process.

- It was analyzed in the Construction Environment $\left(E_{c}\right)$ of the Level of Preventive Action $\left(L_{p a c}\right)$, the constructive and human means for the execution of the work and its disposition in preventive matter. Degree of Exposure parameter $(E)$, analyzes the frequency of exposure to risk in the work unit, in the work environment and in the routes to the work unit. The parameter of the Economic Capacity $\left(E_{e}\right)$, analyzes both 1) the organization of the execution of the work individually, in the work team and as well in the work in general and 2) the amount of individual and collective protection of the workers while working. Both parameters reflect risks of a constructive and human nature.

- Inside the Social Environment $\left(E_{s}\right)$ of the Level of Preventive Action $\left(L_{p a c}\right)$, the risks associated with participation in health and safey risk were identificied. The emotional state of the workers characterize them. The Participative Interest $\left(P_{i}\right)$ parameter analyzes information, training and participation in prevention at the individual and group level. The parameter of the Level of Satisfaction $\left(L_{s}\right)$ analyzes, through an individual and on-site survey, the personal perception or state of mind and the individual and collective perception of the safety and health of the work.

To be evaluated the characteristic values obtained from the risk assessment of the Health and Safety Plan (Absolute Risk) and with the technical observation and the onsite psychosocial survey (Preventive Action Assessment) must be interpreted on each of the risks. This have to be done encompassing the risk classification published by the INSST, which implies a risk assessment in Occupational Safety, Industrial Hygiene, Ergonomics and Psychosociology. This determines that the characteristic value may increase or decrease depending on the degree of incidence. 
The result when relating the Absolute Risk with the evaluation of the Preventive Action indicates the amount of Level of Preventive Action required in the prevention environments evaluated during the construction process, with which the criterion of the control base of the preventive action focuses towards an optimal control situation. From these results, individual recommendation criteria are determined on each of the risks considered, in each of the disciplines on prevention and overall on the construction process.

The focus, reason for this document, lies in the importance of the definition and identification of preventive observation environments. Due to the extensive text that implies the protocol of this new methodology for the evaluation of Occupational Risks adapted to Construction works, it proceeds to show various graphs of results of the implementation of the method on the actual construction process of a work. These graphs show the comparative results of the construction process environments.

- Risk of falling people at different levels (Figure 3).

- Risk of thermal stress (Figure 5).

Data has been taken from a real construction process located in the province of Madrid (Spain), for the construction of 6 semi-detached single-family homes, with three floors, one floor below ground level for garage and storage room, and two floors above ground level for housing. The total constructed area of the building is $1,528.26 \mathrm{~m}^{2}$. The data presented correspond to the collection of data on site from June 17, 2016 to April 27, 2017. Data were collected weekly, for 34 working weeks. The elevation and ground floor plants of the construction and images of the work are presented schematically in Figure 2.

Each graph shows the chronology of the development of the construction site and the construction system inspected in each sample taking using a trend line for the results. The items indicated in the construction phase represent a period of two weeks. The different observation environments and their evolution are identified in the same chronology, with the quantified results of the risks in the environments shown on the left axis. Absolute Environ- ment (blue), Documentary Environment (yellow), Constructive Environment (green) and Social Environment (red). The result of the Level of Preventive Action (black) of the risk assessed and its evolution during the construction process (on a logarithmic scale base 10) its shown.

For the interpretation of the results, and as it has been expressed in previous sections, the values of the Absolute Environment are those previously evaluated at the beginning of the work by the contractor. The Documented Environment is directly proportional and increases the result; The Construction Environment is directly proportional and may increase or decrease the value of the Absolute Environment; the Social Environment is inversely proportional and corrects the value of the Absolute Environment. According to protocoled method, are identified the six degrees of control of the preventive action in the intervals shown with horizontal lines referring to the right axis with respect to the results of the Level of Preventive Action. Control levels indicate the amount of preventive action required in the documentary, constructive, and social settings to achieve the optimal level of control. $L_{p a c}$ values up to $4 \%$ identify that the control base is optimal. For values between $4 \%$ and $12 \%$ it identifies adequate control of the preventive action, for values between $12 \%$ and $20 \%$ more preventive action control is required, for values between $20 \%$ and $36 \%$ more control is required, for values between $36 \%$ and $60 \%$ intensive control is required and for values greater than $60 \%$ exhaustive control of the preventive action is required.

In Figure 3 the evaluation of workers fall risks at different levels is presented. After evaluating the Level of Preventive Action, indications were found that the situation must be controlled with exhaustive levels of preventive action from the beginning of the work to the middle of the construction phase. Following up works phases will need intensive levels of control. The workers fall risk at different levels was present throughout the work and was never possible to eliminate it. The Absolute Environment indicates previous risk values of a moderate nature from the start of the works to the first half. Subsequently, value de-

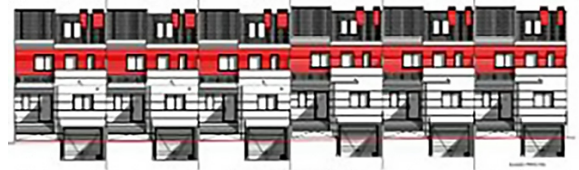

Elevation plan

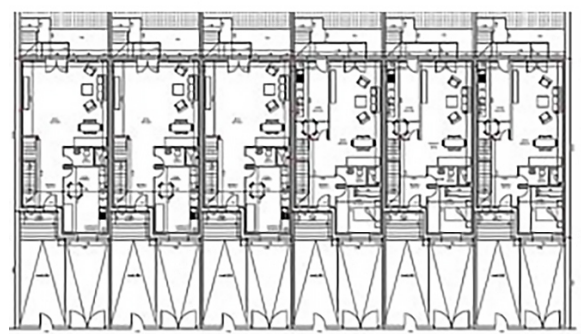

Ground floor plan

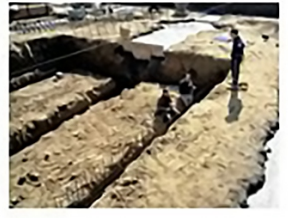

Excavation

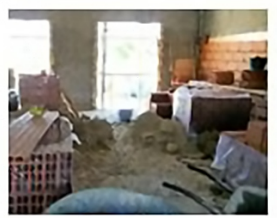

Organization

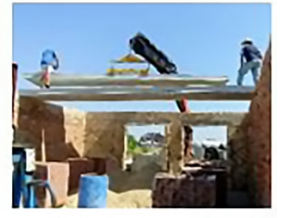

Slab

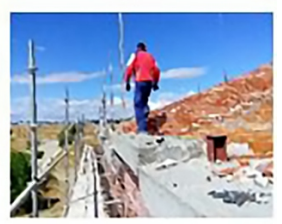

Roof

Figure 2. Plans of the houses. Elevations and Ground Floor. Details 
creases slightly until the end of the work. Across the construction phase, the Documentary Environment indicates that the physical and geometric conditions of the work have a significant impact on the workers fall risk at different levels and its quantification is considerably higher than expected during the first half of the process of building. The Construction Environment shows that collective and individual prevention systems and the frequency of exposure to risk present a lower incidence than expected in the Absolute Environment remaining similar throughout the work phase showing a slightly decrease in the second half of the work. The Social Environment shows that the participation, the state of mind and the perception of the workers related to safety and health issues in the workplace are very low in the first half of the work and have a significant impact on the workers fall risk at different levels, increasing the final value. Workplace images are presented that reflect the incidence of the environments on the workers fall risk at different levels (Figure 4) in facade works (item 1) and roof works (item 2).

In the Figure 3 item 1 under works on facades its is observed that masonry works are being carried out on the façade, on the ground floor and first floor with risks of falling at different heights $\left(E_{d}\right)$. Although the degree of risk exposure is important, a scaffold is available as collective protection $\left(E_{c}\right)$. Participation in prevention is very low. Workers mood is low when working outdoors with high temperatures $\left(E_{s}\right)$. Level of Preventive Action indicates that exhaustive controls are required to be present on all three environments. This is due risk level consideration as intolerable in the Absolute Environment. To correct this trend, it is necessary to increase collective and individual protection measures, encourage participation in prevention through training and constant information, and achieve adequate levels of mood, making the environment positive in the relationship, holding positive conversations (satisfaction private and company personnel). This will cause the values of the Social Environment to increase and correct the trend towards optimal preventive action controls.

In Figure 3 item 2 presenting situation on roof work, there is an evident risk of falling at different heights. The higher the working height, the greater the risk $\left(E_{d}\right)$. There is a scaffold and other safety elements that mitigate the Exposure to the risk of falling at a different level $\left(E_{c}\right)$. Although participation in prevention is very low, the Level of Satisfaction has good values and correct the situation (s). Even when the risk level is evaluated as intolerable only in the Absolute Environment, the Level of Preventive Action indicates that intensive controls are required for all three environments. To correct this trend, it is necessary to increase collective and individual protection measures and encourage participation in prevention through training and constant information together with a boost in workers mood that improve its results. It is important to establish a relationship of empathy and positivism with the workers.

Regarding the evaluation of thermal stress risks (Figure 5), from the beginning of the work to two thirds of the construction phase, the evaluation of the Level of Preventive Action indicates that the situation requires exhaustive levels of preventive action to be controlled. Even increasing more the control level, risk of thermal stress was present throughout the work. The Absolute Environment indi-

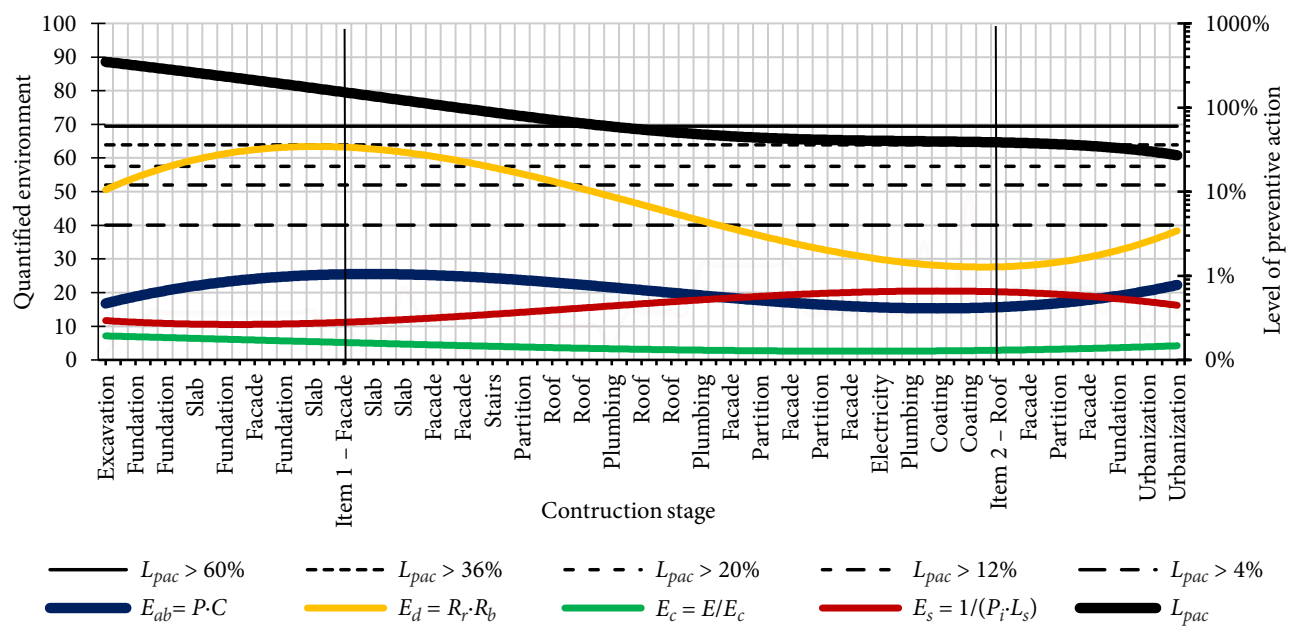

Figure 3. Preventive action environments regarding the risk of worker falls at different levels
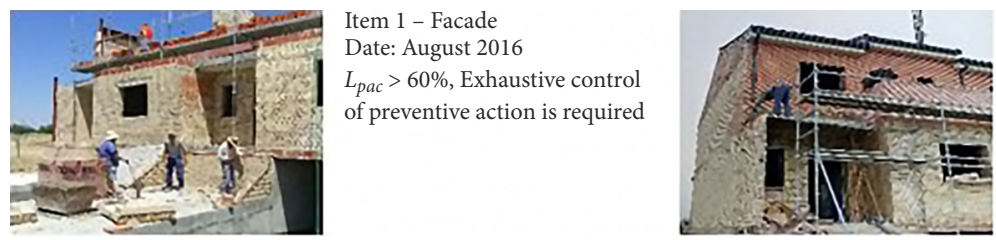

Item 2 - Roof

Item 1 - Facade Date: August 2016

$L_{p a c}>60 \%$, Exhaustive control of preventive action is required

Figure 4. Images of the construction development of the work 
cates previous risk values of a tolerable nature for all work phases. The Documented Environment shows a large part of the construction phases are carried out outside during the summer and winter including rains in the autumn season. The last third portion of construction work coincides with interior work, the completion of the work and the most temperate temperature. The Construction Environment remains constant throughout the work and below the value of the Absolute Environment. In the Social Environment, the mood is low and participation in prevention presents low values, negatively influenced by the thermal conditions on summer, autumn and winter. Images of the work are presented that reflect the incidence of the environments on the risk of thermal stress (Figure 6) in facade works (item 3) and roof works (item 4).

It can be seen in the image item 3 on works on facades, that masonry works are being carried out abroad, affecting the risks of thermal stress $\left(E_{d}\right)$ due to the large work surface. Although the degree of risk exposure is important, workers usually rest in the shade $\left(E_{c}\right)$. Participation in prevention is very low and the mood is low when working outdoors with high temperatures $\left(E_{s}\right)$. Although considering it a tolerable risk in the Absolute Environment, the Level of Preventive Action indicates that exhaustive controls are required for all three environments. To correct this trend, it is necessary to increase collective and individual protection measures by installing shading and promoting participation in prevention through training, information and positive conversations. The interest in prevention and the level of satisfaction will have a greater presence and will help correct the situation.
On roofing works presented in the image item 4 it can be seen that coating works are being carried out on the ground floor roof. The outdoor temperature is adequate, so the position of the job according to its height conditions moderately the risks of thermal stress $\left(E_{d}\right)$. The degree of risk exposure has decreased and security conditions have improved, so its incidence of thermal risk is low $\left(E_{c}\right)$. Participation in safety is still low; however, the safety conditions of the work have improved as they are in the last stages of construction improving the Level of Satisfaction. The incidence on thermal risk improves, as the jobs are safer $\left(E_{s}\right)$. Although risk consideration is tolerable in the Absolute Environment, the Level of Preventive Action indicates that more control is required for the three evaluation environments (documentary, constructive and social). To correct this trend, it is necessary to increase individual protection measures and encourage participation in prevention.

\section{Conclusions}

This new risk assessment method proposed, adapted to building works, called Level of Preventive Action, by means of a new mathematical formula for risk assessment, unifies and connects the risk assessment parameters using a corrective parameter which determines the preventive level (for Safety at Work, Industrial Hygiene, Ergonomics and Psychosociology) for the construction works, with the aim of establishing timely control and prevention environments and moving towards an optimum risk prevention situation.

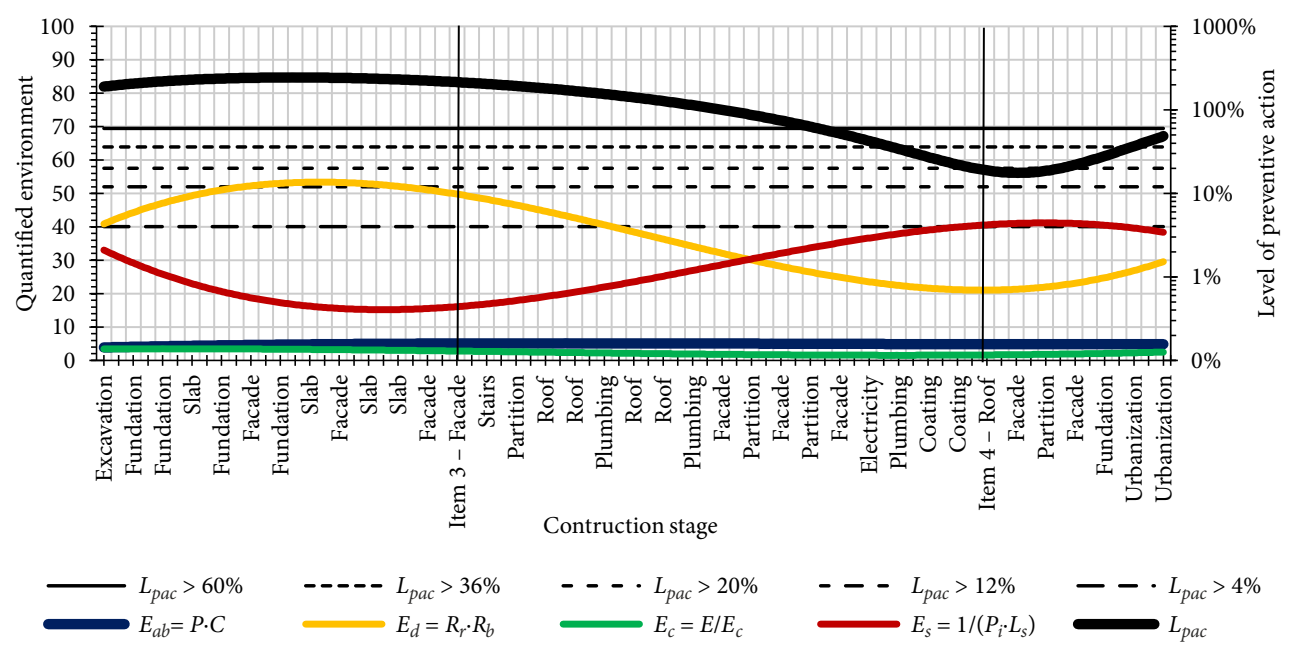

Figure 5. Preventive action environments regarding the risk of thermal stress
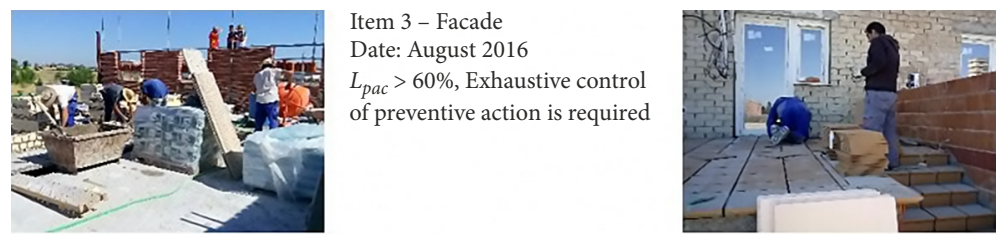

Item 4 - Cover

Date: March 2017

$L_{p a c}<60 \%$, More preventive

of preventive action is required

Figure 6. Images of the construction development of the work 
The new method is based on technic observation and data gathering of the prevention environments, and on a psychosocial survey on site. The main factor for optimal control is the workers' participation in risk prevention, which is the most efficient correction parameter.

It is a more flexible method in its application. It is also more sensitive to risks detection in all scenarios in the construction process. It also manages to establish a relationship between the different levels of preventive action and the risk perception that workers have.

A new concept of observation has been established for preventive action called Level of Preventive Action Environment; and that differs from the phases of the technicalbuilding process, which allows to identify and understand, in a simpler way, the insecure contexts. The Environments of the Preventive Action are $E_{a b}$ - the Absolute Environment (related to the Draft and the Execution Project), $E_{d}$ - Documentary Environment (related to the Project Hiring process), $E_{c}-$ Constructive Environment (related to the application of construction systems during building construction works), $E_{s}$ - Social Environment (related to participation in prevention and the level of satisfaction of workers during building construction works) and $E_{l c}-$ Live Cicle Environment (use of the building); and they are related to the periods of the construction process.

It has been possible to quantify the amount of risk involved in each of the environments during a construction process and its corresponding Level of Preventive Action associated with each assessed risk. This can be understand this based on the results that the evolution of risks in a construction process is highly variable over time. The evaluation observed from the different aspects of the environments offers us the possibility of relating them and understanding what the Level of Preventive Action is required to achieve the optimal control situation.

The disciplines related to health and safety in a work environment taken into account are Safety at Work, Industrial Hygiene, Ergonomics and Psychosociology. In addition, the study of bibliography as well the different investigations on risk assessment methodologies and their adaptability to construction works. Is also relevant the use of the method of the Level of Preventive Action focuses on evaluating globally the construction characteristics, the location of the positions work, the degree of exposure to risk, collective and individual security systems, levels of participation in safety and the Level of Satisfaction of workers.

Not only is the design of the building, the construction systems and the security elements that are going to be used during the construction process important, but the state of mind and the levels of participation in security matters imply relevant degrees of correction in the Risks evaluation. It is essential to learn to observe construction, not only from a technical-constructive point of view, but it is decisive to observe and analyze the interest shown by the worker regarding their participation in health and safety individually or collectively, and their behavior based on your mood; and how it affects constructive development.

Regarding the results of implementation, it should be noted that the Preventive Action Level methodology has great sensitivity to identify situations that require immediate preventive actions. In decision making, preventive action involves improving any of the observation environments. For this, it is important to communicate and establish training strategies for workers so that they know how to improve prevention environments.

It is essential, in the documentary environment, to identify and improve the preconditions regarding the geometry and constructive characteristics of the building, in the conception and design phase. In the construction environment, preventive action must improve the conditions of exposure to the risk of workers and the systems of collective and individual protection during construction work. Finally, the participation in prevention and the emotional states of the workers during construction work must be improved with positive communication strategies in the social environment.

One of the characteristics of the risk assessment method of the Level of Preventive Action is its immediate nature and adaptability to the different construction systems, planning and development of a construction site. It is able to identify from each aspect of the observation environments in regard of the result of the Level of Preventive Action, what is the control base and the amount of preventive action that is required on each of them to ensure that the control situation is optimal.

\section{Acknowledgements}

The authors wish to acknowledge everybody who has collaborated in this study: Mr. Pedro Antonio Beguería Latorre, Mr. Alfonso Asperilla López, Colegio Oficial de Aparejadores, Arquitectos Técnicos y Graduados en Ingeniería de la Edificación de Toledo and Department of Architectural Constructions of the Universidad Politécnica de Madrid.

\section{Funding}

This work was supported by the Universidad Politécnica de Madrid [grant number VAGI19MNGG].

\section{Contribution}

Dr. Carpio was responsible for: conception and design of the work, acquisition of data, results analysis, interpretation, discussion and conclusion, and he wrote the first draft of the article. Dr. González conducted the detailed analysis of the work and wrote the successive drafts, discussion and conclusion. Dr. Prieto checked the related arcticles, provided the corresponding analysis and refined the submission to Journal. Dr. Martínez was responsable for revising the work critically. 


\section{Disclosure statement}

The authors do not have any competing financial, professional, or personal interests from other parties.

\section{References}

Abbas, R., Zalat, M., \& Ghareeb, N. (2013). Non-fatal occupational injuries and safety climate: A cross-sectional study of construction building workers in Mit-Ghamr City, Dakahlia Governorate, Egypt. Open Journal of Safety Science and Technology, 3(4), 69-79. https://doi.org/10.4236/ojsst.2013.34009

Abdurrahman, M. (2009). Classifying accident risks in high-rise building construction. Journal Penelitian Teknik Sipil, 4(2), 126-133.

Act 31 of $8^{\text {th }}$ November 1995 on prevention of occupational risks. Official State Gazette (BOE), 10 ${ }^{\text {th }}$ November 1995. BOE Number 269. Spain. https://www.insst.es/documents/94886/ $200952 /$ Act $+31+$ of +8 th + November $+1995+$ on + prevention + o f+occupational+risks

Allen, E., \& Iano, J. (2019). Fundamentals of building construction: materials and methods. John Wiley \& Sons, Inc.

Asilian, H., Khosravi, Y., Hassanzadeh, N., Hajizadeh, E., \& Behzadan, A. H. (2018). Factors affecting unsafe behavior in construction projects: development and validation of a new questionnaire. International Journal of Occupational Safety and Ergonomics, 26(2), 219-226.

https://doi.org/10.1080/10803548.2017.1408243

Avdiu, B., \& Nayyar, G. (2020). When face-to-face interactions become an occupational hazard: Jobs in the time of COVID-19 (Policy Research Working Paper 9240). World Bank Group, Finance, Competitiveness and Innovation Global Practice. https://doi.org/10.1596/1813-9450-9240

Barandan, S., \& Usmen, M. (2006). Comparative injury and fatality risk analysis of building trades. Journal of Construction Engineering and Management, 132(5), 533-539. https://doi.org/10.1061/(ASCE)0733-9364(2006)132:5(533)

Bhandari, S., Hallowell, M., Van-Boven, L., \& Welker, K. M. (2020). Using augmented virtuality to examine how emotions influence construction-hazard identification, risk assessment, and safety decisions. Journal of Construction Engineering and Management, 146(2), 04019102.

https://doi.org/10.1061/(ASCE)CO.1943-7862.0001755

Birhane, E. G., Yang, L., Geng, J. C., \& Zhu, J. Q. (2020). Causes of construction injuries: A review. International Journal of Occupational Safety and Ergonomics.

https://doi.org/10.1080/10803548.2020.1761678

Carpio, A. J. (2017). Nueva metodología de evaluación de riesgos laborales adaptada a obras de edificación, Nivel de la Acción Preventiva [Doctoral thesis]. Universidad Politécnica de Madrid, Spain.

Carpio, A. J., \& González, M. N. (2017). Critical analysis of risk assessment methods applied to construction works. Journal of Construction, 16(1), 104-114. https://doi.org/10.7764/RDLC.16.1.104

Carpio, A. J., \& González, M. N. (2020). Development of the protocol of the occupational risk assessment method for construction works: Level of Preventive Action. International Journal of Environmental Research and Public Health, 17, 6369. https://doi.org/10.3390/ijerph17176369

Carpio, A. J., González, M. N., Moreu, C., \& Hosokawa, K. (2017). Suitability and discrepancy of health and safety risk assessment methods applied to construction works. Dyna, 92(2), 214-219. https://doi.org/10.6036/8201

Castellano, J. (2008). Análisis del régimen jurídico del proceso constructivo de la edificación. Colegios de Aparejadores y Arquitectos técnicos de Málaga y Girona, España.

Chavarría, R. (1986). NTP-176. Evaluación de las condiciones de trabajo: Método de los perfiles de puestos. INSHT (Instituto Nacional de Seguridad e Higiene en el Trabajo), Ministerio de Trabajo y Asuntos Sociales, España.

Claudino Véras, J. (2012). Método para la evaluación de riesgos laborales en obras de construcción de grandes viaductos [Doctoral thesis]. Universitat Politècnica de Catalunya, Spain.

Cuchí, A. (2010). Cambio Global España 2020/2050. Sector Edificación. Societat Orgánica, Barcelona.

Engeda, G., Yang, L., Geng, J., \& Zhu, J. (2020). Causes of construction injuries: Review. International Journal of Occupational Safety and Ergonomics.

https://doi.org/10.1080/10803548.2020.1761678

Espinheira, I., Duarte, J., \& Baptista, J. S. (2020). Risk assessment associated with the use of manual commands in an industry. In P. Arezes, J. S. Baptista, M. P. Barroso, P. Carneiro, P. Cordeiro, N. Costa, R. B. Melo, A. S. Miguel, \& G. Perestrelo (Eds.), Occupational and environmental safety and health II. Studies in systems. Decision and Control (Vol. 277, pp. 115121). Springer. https://doi.org/10.1007/978-3-030-41486-3_13

Faber, M., \& Stewart, M. (2003). Risk assessment for civil engineering facilities: critical overview and discussion. Reliability Engineering \& System Safety, 80(2), 173-184.

https://doi.org/10.1016/S0951-8320(03)00027-9

Fakhratov, M., Sinenko, S., \& Akbari, M. (2020). Determination of fundamental criteria in the selection of a construction system. E3S Web of Conferences, 157, 06025.

https://doi.org/10.1051/e3sconf/202015706025

Fine, W. T. (1971). Mathematical evaluation for controlling hazards. Journal of Safety Research, 3(4), 157-166. https://doi.org/10.21236/AD0722011

Forteza, F. J., Sesé, A., \& Carretero-Gómez, J. (2016). CONSRAT. Construction sites risk assessment tool. Safety Science, 89, 338-354. https://doi.org/10.1016/j.ssci.2016.07.012

Forteza, F. J., Carretero, J., \& Sesé, A. (2017). Occupational risks, accidents on sites and economic performance of construction firms. Safety Science, 94, 61-76. https://doi.org/10.1016/j.ssci.2017.01.003

Gao, Y. F., González, V. A., \& Yiu, T. K. (2019). Exploring the relationship between construction workers' personality traits and safety behavior. Journal of Construction Engineering and Management, 146(3), 04019111.

https://doi.org/10.1061/(ASCE)CO.1943-7862.0001763

Gillen, M., Baltz, D., Gassel, M., Kirsch, L., \& Vaccaro, D. (2002). Perceived safety climate, job demands, and coworker support among union and nonunion injured construction workers. Journal of Safety Research, 33(1), 33-51. https://doi.org/10.1016/S0022-4375(02)00002-6

Gomes de Oliveira, C. (2010). Propuesta de una metodología integrada para la evaluación del riesgo professional [Doctoral thesis]. Universidad de León, Spain.

Gómez-Cano, M., González, E., López, G., \& Rodríguez, A. (1996). Evaluación de riesgos laborales. Instituto Nacional de Seguridad e Higiene en el Trabajo, Spain.

Gürcanli, G. E., \& Müngen, U. (2009). An occupational safety risk analysis method at construction sites using fuzzy sets. International Journal of Industrial Ergonomics, 39(2), 371-387. https://doi.org/10.1016/j.ergon.2008.10.006 
Hardison, D., Hallowell, M., \& Littlejohn, R. (2020). Does the format of design information affect hazard recognition performance in construction hazard prevention through design reviews? Safety Science, 121, 191-200.

https://doi.org/10.1016/j.ssci.2019.09.008

Haslam, R., Hide, S., Gibb, A., Gyi, D., Pavitt, T., Atkinson, S., \& Duff, A. R. (2005). Contributing factors in construction accidents. Applied Ergonomics, 36(4), 401-415. https://doi.org/10.1016/j.apergo.2004.12.002

Jannadi, O., \& Almishari, S. (2003). Risk assessment in construction. Journal of Construction Engineering and Management, 129(5), 492-500.

https://doi.org/10.1061/(ASCE)0733-9364(2003)129:5(492)

Jung, Y., Kang, S., Kim, Y., \& Park, C. (2008). Assessment of safety management information systems for general contractors. Safety Science, 46(4), 661-674.

https://doi.org/10.1016/j.ssci.2007.06.009

Larsson, T., \& Field, B. (2002). The distribution of occupational injury risks in the Victorian construction industry. Safety Science, 40(5), 439-456.

https://doi.org/10.1016/S0925-7535(01)00015-7

Lee, W., Migliaccio, G. C., Lin, K. Y., \& Seto, E. Y. W. (2020). Workforce development: understanding task-level job demands-resources, burnout, and performance in unskilled construction workers. Safety Science, 123, 104577.

https://doi.org/10.1016/j.ssci.2019.104577

Ley 8/2013, de 26 de junio, de rehabilitación, regeneración y renovación urbanas. Official State Gazette (BOE), 27 th June 1993. BOE Number 153. Spain. https://www.boe.es/eli/es/1/2013/06/26/8/con

Lucchi, E. (2016). Multidisciplinary risk-based analysis for supporting the decision making process on conservation, energy efficiency, and human comfort in museum buildings. Journal of Cultural Heritage, 22, 1079-1089.

https://doi.org/10.1016/j.culher.2016.06.001

Lucchi, E. (2020). Environmental risk ranagement for ruseums in historic buildings through an innovative approach: A case study of the Pinacoteca di Brera in Milan (Italy). Sustainability, 12(12), 5155. https://doi.org/10.3390/su12125155

Lucchini, R. G., \& London, L. (2014). Global occupational health: Current challenges and the need for urgent action. Annals of Global Health, 80(4), 251-256.

https://doi.org/10.1016/j.aogh.2014.09.006

Martínez-Aires, M. D., López-Alonso, M., \& Martínez-Rojas, M. (2018). Building information modeling and safety management: a systematic review. Safety Science 101, 11-18. https://doi.org/10.1016/j.ssci.2017.08.015

Mihić, M. (2020). Classification of construction hazards for a universal hazard identification methodology. Journal of Civil Engineering and Management, 26(2), 147-159.

https://doi.org/10.3846/jcem.2020.11932

Minh, T., \& Yingbin, F. (2019). Impact of project complexity on construction safety performance: Moderating role of resilient safety culture. Journal of Construction Engineering and Management, 146(2), 04019103.

https://doi.org/10.1061/(ASCE)CO.1943-7862.0001758

Mohamed, S., Ali, T. H., \& Tam, W. Y. V. (2009). National culture and safe work behaviour of construction workers in Pakistan. Safety Science, 47(1), 29-35.

https://doi.org/10.1016/j.ssci.2008.01.003

Mohammadi, A., \& Tavakolan, M. (2020). Identifying safety archetypes of construction workers using system dynamics and content analysis. Safety Science, 129, 104831.

https://doi.org/10.1016/j.ssci.2020.104831
Molina, J. (2006). Historia de la seguridad en el trabajo en España. Dirección General de Trabajo y Prevención de Riesgos Laborales, Spain.

Mushayi, T., Deacon, C., \& Smallwood, J. (2018). The effectiveness of health and safety training and its impact on construction workers' attitudes, and perceptions. In 8th International Conference on Engineering, Project, and Product Management (EPPM 2017). https://doi.org/10.1007/978-3-319-74123-9_25

Nogareda, C. (1988). NTP 210: Análisis de las condiciones de trabajo: método de la A.N.A.C.T. Ed. INSHT (Instituto Nacional de Seguridad e Higiene en el Trabajo), Ministerio de Trabajo y Asuntos Sociales, Spain.

Oliveira, C. (2010). Propuesta de una metodología integrada para la evaluación del riesgo professional [Doctoral thesis]. Universidad de León, Spain.

Paolillo, A., Silva, S. A., Carvalho, H., \& Pasini, M. (2020). Exploring patterns of multiple climates and their effects on safety performance at the department level. Journal of Safety Research, 72, 47-60. https://doi.org/10.1016/j.jsr.2019.12.009

Pinto, A. (2014). QRAM - a Qualitative Occupational Safety Risk Assessment Model for the construction industry that incorporate uncertainties by the use of fuzzy sets. Safety Science, 63, 57-76. https://doi.org/10.1016/j.ssci.2013.10.019

Pinto, A., Ribeiro, R., \& Nunes, I. (2012). Fuzzy approach for reducing subjectivity in estimating occupational accident severity. Accident Analysis \& Prevention, 45, 281-290.

https://doi.org/10.1016/j.aap.2011.07.015

Real Decreto 314/2006, de 17 de marzo, por el que se aprueba el Código Técnico de la Edificación. Official State Gazette (BOE), 28th March 2006. BOE Number 74. Spain. https://www.boe. es/eli/es/rd/2006/03/17/314

Reyes, J., San José, J., Cuadrado, J., \& Sancibrián, R. (2014). Health \& safety criteria for determining the sustainable value of construction projects. Safety Science, 62, 221-232. https://doi.org/10.1016/j.ssci.2013.08.023

Salanova, M., Gracia, E., \& Lorente, L. (2005). Metodología Wont para la evaluación y prevención de riesgos psicosociales. Gestión Práctica de Riesgos Laborales, 14, 22-32.

Salanova, M., Gracia, E., \& Lorente, L. (2007). Riesgos psicosociales en trabajadores de la construcción. Gestión Práctica de Riesgos Laborales, 44, 12-19.

Sanni-Anibire, M. O., Mahmoud, A. S., Hassanain, M. A., \& Salami, B. A. (2020). A risk assessment approach for enhancing construction safety performance. Safety Science, 121, 15-29. https://doi.org/10.1016/j.ssci.2019.08.044

Segarra, M., Villena, B. M., González, M. N., Romero, Á., \& Rodríguez, Á. (2017). Occupational risk-prevention diagnosis: A study of construction SMEs in Spain. Safety Science, 92, 104-115. https://doi.org/10.1016/j.ssci.2016.09.016

Silva, S., Araújo, A., Costa, D., \& Meliá, J. (2013). Safety climates in construction industry: Understanding the role of construction sites and workgroups. Open Journal of Safety Science and Technology, 3(4), 80-86.

https://doi.org/10.4236/ojsst.2013.34010

Simanaviciene, R., Liaudanskiene, R., \& Ustinovichius, L. (2014). Assessing reliability of design, construction, and safety related decisions. Automation in Construction, 39, 47-58. https://doi.org/10.1016/j.autcon.2013.11.008

Swuste, P., Groeneweg, J., Gulijk, C., Zwaard, W., Lemkowitz, S., \& Oostendorp, Y. (2020). The future of safety science. Safety Science, 125, 104593. https://doi.org/10.1016/j.ssci.2019.104593 
Tepeli, E., Taillandier, F., \& Breysse, D. (2019). Multidimensional modelling of complex and strategic construction projects for a more effective risk management. International Journal of Construction Management.

https://doi.org/10.1080/15623599.2019.1606493

Úbeda de Mingo, P. (2002). Espacio: Roles, ritos y valores entre los constructores de edificios. Colegio Oficial de Aparejadores y Arquitectos Técnicos de Granada, Granada.

Williams, T. (1993). Risk-management infrastructures. International Journal of Project Management, 11(1), 5-10. https://doi.org/10.1016/0263-7863(93)90003-6

Xia, N., Xie, Q., Hu, X., Wang, X., \& Meng, H. (2020). A dual perspective on risk perception and its effect on safety behavior: A moderated mediation model of safety motivation, and supervisor's and coworkers' safety climate. Accident Analysis \& Prevention, 134, 105350.

https://doi.org/10.1016/j.aap.2019.105350

Zhao, D., McCoy, A. P., Kleiner, B. M., Mills, T. H., \& Lingard, H. (2016). Stakeholder perceptions of risk in construction. Safety Science, 82, 111-119. https://doi.org/10.1016/j.ssci.2015.09.002

Zou, P., Zhang, G., \& Wang, J. (2007). Understanding the key risks in construction projects in China. International Journal of Project Management, 25(6), 601-614.

https://doi.org/10.1016/j.ijproman.2007.03.001 